Chirurgia (2019) 114: 251-258

No. 2, March - April

Copyright $\odot$ Celsius

http://dx.doi.org/10.21614/chirurgia.114.2.251

\title{
Abdominal Actinomycosis Mimicking Colon Cancer
}

\author{
Eugen Târcoveanu, Alin Vasilescu, Dan Andronic, Cristian Lupașcu, Delia Ciobanu, Nuțu Vlad, Costel Bradea
}

First Surgical Clinic,"St. Spiridon" University Hospital, Iași, Romania

"Gr. T. Popa" University of Medicine and Pharmacy Iași, Romania

Corresponding author:

Vasilescu Alin, MD,PhD

First Surgical Clinic

"St. Spiridon" University Hospital

"Gr. T. Popa" University of Medicine and Pharmacy lasi

1, Independentei Street, no 1

E-mail: vasilescu.alin@gmail.com

\section{Rezumat}

Actinomicoza abdominală imită cancerul de colon

Introducere: Actinomicoza abdominală este o afecțiune inflamatorie granulomatoasă rară produsă de o bacterie anaerobă Gram pozitivă Actinomyces israelii, care se manifestă ca tumori inflamatorii sau formează abcese. Evoluția este lentã şi constã în extensie inflamatorie de contiguitate, fãrã limitã de organ, ce pretează la confuzia cu leziuni maligne abdominale.

Material şi metodă: Am efectuat un studiu retrospectiv a pacienților cu actinomicoză abdominală operați în Clinica I Chirurgie Spitalul Universitar "Sf. Spiridon” din Iaşi, între 1980 şi 2018. Au fost înregistrate 13 cazuri (4 bărbați şi 9 femei) cu vârsta medie de 44,07 ani care s-au internat cu tumori abdominale (7 cazuri) şi boala inflamatorie pelvină (6 cazuri).

Rezultate: Am identificat ca factori predispozanți: dispositive intrauterine menținute timp de 10 ani (6 cazuri), corpuri străine - 2 cazuri (o scobitoare de lemn care probabil a perforat colonul, calculi biliari pierdut în peritoneu), diabet (3 cazuri), imunodepresia. Pacienții au fost operați prin laparotomie (9 cazuri) sau laparoscopic (4 cazuri). Descriem cinci dintre aceste cazuri de actinomicoză care au mimat un cancer de colon: localizare ileo - cecală - 3 cazuri, colon transvers - un caz şi mare epiploon - un caz, care au urmat tratament specific cu penicilină, având o evoluție bună.

Concluzii: Actinomicoza abdominală trebuie întotdeauna inclusă în diagnosticul diferențial al tumorilor abdominale. Diagnosticul preoperator, dificil, dar posibil, poate evita intervenția chirurgicală. Tratamentul cu antibiotice este necesar pentru vindecarea bolii. Controlul postoperator este obligatoriu, cu recidive posibile.
Received: 03.03.2019 Accepted: 08.04.2019 www.revistachirurgia.ro 
Cuvinte cheie: actinomicoză abdominală, cancer de colon, tumori inflmatorii

\section{Abstract}

Introduction: Abdominal actinomycosis is a rare granulomatous inflammatory disease caused by a Gram-positive anaerobic bacterium Actinomyces israelii, manifesting as inflammatory mass, or abscess formation. Evolution is slow and steady in inflammatory contiguous extension without limit organ that lends itself to confusion with abdominal malignancies.

Methods: We performed a retrospective study on the patients with abdominal actinomycosis operated in the First Surgical Clinic, "St. Spiridon" University Hospital Iasi; between 1980 - 2018 there have been 13 cases ( 4 men and 9 women) with a mean age 44.07 years admitted for abdominal tumors ( 7 cases) or pelvic inflammatory disease (6 cases).

Results: We identified as predisposing factors: IUD maintained over 10 years (6 cases), foreign bodies -2 cases (a toothpick probably perforated colon, gallstones lost in peritoneum), diabetes (3 cases), immunodepression. All cases were operated by laparotomy (9 cases) or laparoscopic approach ( 4 cases). We describe five of these cases of actinomycosis that had been mimicking a colon cancer: ileo - cecal - 3 cases, transverse colon - one case and on the greater omentum - one case, followed by specific treatment with penicillin, with good evolution.

Conclusions: Abdominal actinomycosis should always be included in the differential diagnosis of abdominal tumors. Preoperative diagnosis, difficult but possible, can avoid surgery. Treatment with antibiotics is necessary for the healing of the disease. Postoperative control is mandatory, with relapses possible.

Key words: abdominal actinomycosis, colon cancer, inflammatory tumor

\section{Introduction}

Abdominal Actinomycosis is a rare granulomatous inflammatory disease caused by an Grampositive anaerobic bacterium Actinomyces israelii, manifesting as pseudo-inflammatory tumor, or abscess formation. Evolution is slow and steady in inflammatory contiguous extension without limitation on one organ, character prone to confusion with abdominal malignancies $(1,2)$. In the cases of infiltrative abdominal tumors abdominal actinomycosis should be considered as a differential diagnosis (1).

\section{Methods}

We performed a retrospective study on the patients with abdominal actinomycosis operated in the First Surgical Clinic, "St. Spiridon" University Hospital Iasi between 1980 - 2018. We have analyzed the clinic- pathological and therapeutic data of the cases pathological or microbiological confirmed having actinomycosis.

\section{Results}

There have been 13 cases of abdominal actinomycosis operated: 4 men and 9 women with age between 18 and 60 years (mean age 44.07 years). Patients were admitted with abdominal tumors ( 7 cases) or pelvic inflammatory disease (6 cases).

In previous reports, we have noticed an increase in the pelvic actinomycosis associated with long - term intrauterine devices (IUDs) (3). Among other factors identified in our statistics were: diabetes mellitus (3 cases), foreign bodies - 2 cases (a wood toothpick that probably perforated the colon, gallstones lost in the peritoneum), immunodepression. Most cases were admitted with the diagnosis of abdominal 
malignant tumor, colic or genital. Diagnosis was rarely suspected on imaging, but it was determined by culture from surgically drained pus (3 cases) and in all cases by identifying colonies of Actinomyces israelii on pathology.

Surgery had been performed by open approach (9 cases) or laparoscopic approach (4 cases). We performed drainage of actinomycosis abscess (3 cases), adnexectomy and drainage (4 cases), colic resections (3 cases), or resections of the pseudotumor (2 cases). All patients were treated with penicillin for 15-38 days. We recorded 3 relapses that required reintervention in those who had short-term penicillin treatment.

We present the cases with the suspicion of colon tumors located: ileo - cecal (3 cases), transverse colon one case and on the greater omentum - one case.

Case 1. A 55-year-old man patient was admitted in emergency with complaints of abdominal pain, nausea, vomiting and absence of bowel movements. He had a 2 months history of fatigue, loss of appetite and diffuse abdominal pain, which progressively worsened. Physical examination revealed a distended abdomen with diffuse tenderness in the lower part. There was a poorly defined mass in the right lower quadrant.

Lab work showed an elevated white count of $13770 / \mathrm{mmc}$, mild anemia with a $\mathrm{Hb}$ of 11.3 $\mathrm{g} \%$ and an elevated sedimentation rate of 105 $\mathrm{mm} / \mathrm{h}$. The abdominal ultrasound (Fig. 1) described a solid, heterogeneous mass measuring $81 / 43 \mathrm{~mm}$, surrounded by fluid, which was $3 \mathrm{~cm}$ deep and underneath the umbilical scar. With conservative measures his bowel obstruction improved. CT-scan of the abdomen and pelvis (Fig. 2) described a soft tissue, heterogeneous mass involving an ileal loop medial to the cecum, with thickening of the intestinal wall of more than $5.5 \mathrm{~cm}$. This irregular mass extended into the peritoneum. The adjacent mesentery had inflammatory changes and there was thickening of the anterior-superior wall of the bladder.

The patient underwent elective exploratory surgery with evidence of an ileal mass, involving the omentum and adhering to the abdominal wall. Within this ileal mass, there was an abscess with thick granular drainage, which was sent for culture. There were two additional

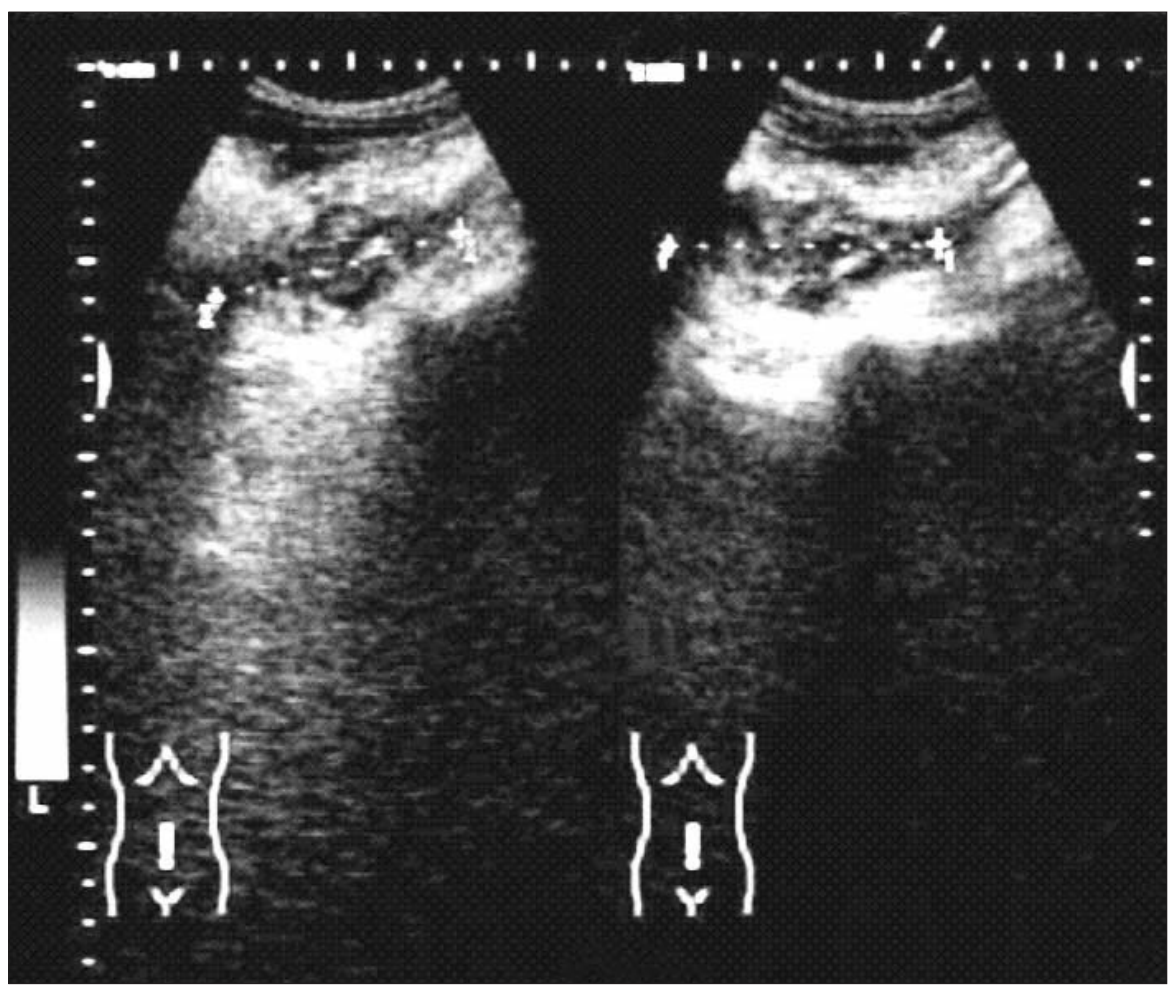

Figure 1. Abdominal ultrasound heterogeneous abdominal mass surrounded by fluid 
Figure 2. CT scan - heterogeneous mass involving ileal loop; inflammatory changes of the mesentery and intestinal wall

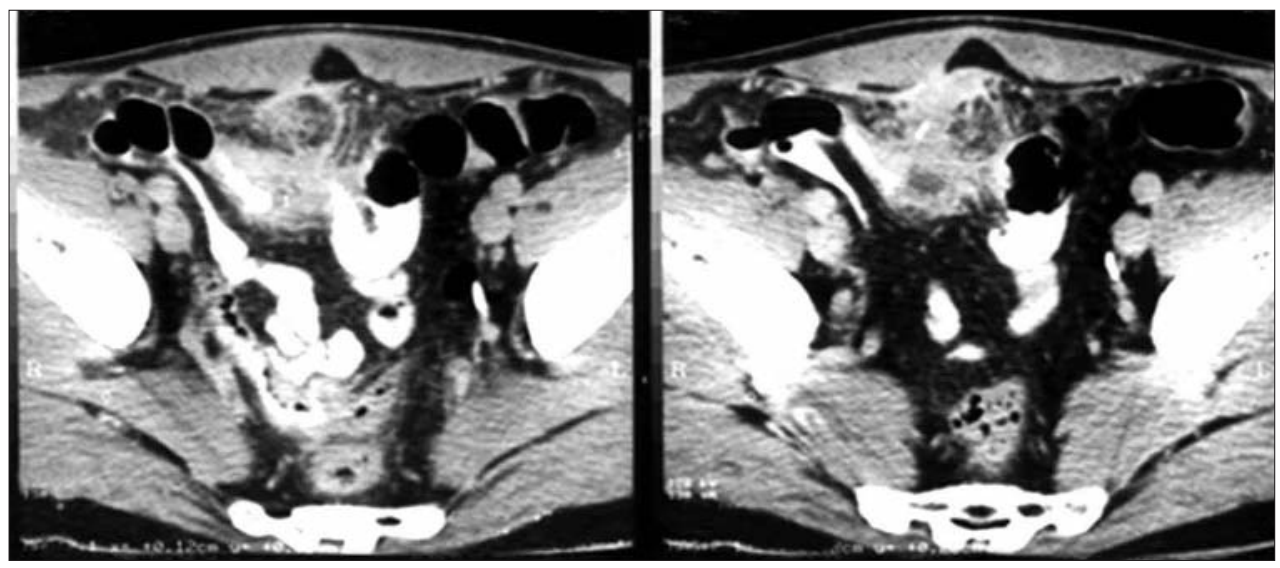

whitish nodules measuring $1 \mathrm{~cm}$ each, located within the mesentery. We proceeded with a 30 $\mathrm{cm}$ resection of the ileum, followed by an ileo-ileal anastomosis with redundant safety margins. Frozen sections of the parietal peritoneum were negative for malignancy. The patient was started on Penicillin with a favorable postoperative course. The patient was discharged on the 10th postoperative day. Final pathology revealed a diffuse, nonspecific inflammatory process of the intestinal wall with a granulomatous reaction and micro-abscesses of the serosa and mesentery. In addition, there was a granulomatous inflammation of the omentum and of the parietal peritoneum. Isolated colonies of Actinomyces israelii were also identified.

The patient did not comply with his therapy with Penicillin. Two months later, he presented with intestinal obstruction induced by recurrent inflammation and adhesions secondary to actinomycosis. He underwent an ileo-cecal resection with latero-lateral anastomosis. Early post operatively, the patient was transferred to infectious disease clinic and had one month of Penicillin with a daily dose of 10 million units. He was readmitted with a pelvic abscess, involving the Douglas pouch, which required drainage. He had a quick recovery and three months later, the patient was asymptomatic, with no evidence of recurrence.

Case 2. A 41-year-old man patient presented with complaints of right lower quadrant pain, poor appetite and weight loss. He reported an insidious onset of his symptoms two months before, with fatigue, headache, weight loss and right lower quadrant pain. He developed a local abdominal mass which progressively enlarged. The patient is hospitalized with the diagnosis of colon cancer. On admission, he was pale, wasted and with a temperature of $36.9^{\circ} \mathrm{C}$. Physical examination revealed an $8 \mathrm{~cm}$ hard mass located in the right lower quadrant. The mass had poorly defined borders, was tender to palpation and adherent to deep structures. Lab work, including renal and liver function, was unremarkable. On barium enema the cecum could not be filled with contrast media. On compression a large, irregular filling defect was identified in the cecum extending up to $1 \mathrm{~cm}$ above the ileo-cecal valve. It's appearance, as well as the presence of multiple, small ulcerations, were suggestive of a cecal tumor. The patient underwent an elective laparotomy. There was evidence of a fixed mass involving the distal ileum and the cecum. We proceeded with a right hemicolectomy with ileo-transverse anastomosis.

The macroscopic examination of the specimen revealed a subserosal, yellowish, granular mass. Microscopy was consistent with cecal actinomycosis. The patient was started on Penicillin at 1 million units/day. The patient had a favorable postoperative course. He continued 6 more weeks of antibiotics. Follow-up at 3, 6 and 12 months revealed a stable clinical status with no evidence of recurrence.

Case 3. A 31-year-old female patient presented with acute cholecystitis. During open cholecystectomy, as an incidental finding, 
there was evidence of a fixed ileo-cecal mass, suspicious for plastic peritonitis associated with acute appendicitis, which could not be addressed during the same surgery. She presented 3 months later with complaints of right lower quadrant pain radiating to the right thigh, loss of appetite, fatigue, constipation and weight loss. Physical examination revealed a right lower quadrant irregular hard mass, which was tender on palpation, and adhering to deep structures. Barium enema with compression views revealed filling defects in the cecum and adhesions of the terminal ileum. The patient underwent an elective surgery. There was evidence of a large, right lower quadrant mass involving the cecum and the terminal ileum and causing their adherence to deep muscles. We detached the cecum and opened a retrocecal cavity which was extending towards the right flank. This cavity contained a thick, granular mass which was evacuated and further drained. In addition, we performed an ileo-transverse anastomosis. Histopathology revealed actinomycosis. Postoperatively, we started penicillin treatment of 3 million units/ day, streptomycin at $1 \mathrm{~g} /$ day and potasium iodine at $6 \mathrm{~g} /$ day. The patient had a quick recovery with healing of the surgical incision at 14 days. After discharge, the patient continued the treatment with penicillin and potasium iodine for one additional month. Six months later, she was asymptomatic and reported weight gain.

Case 4. 59-year-old male patient with type II diabetes is admitted with pain in right upper quadrant pain, with a palpable $6 / 8 \mathrm{~cm}$ mass, indefinite margins. He is admitted with the suspicion of right colon cancer. Abdominal ultrasound reveals a mass $53 / 45 \mathrm{~mm}$ with hypoechogenic areas. Barium enema shows a right colic angle external compression.

Laparoscopy reveals a large omental tumor in the vicinity of the right colic angle adhering to the anterior abdominal wall; it has been removed in an (Fig. 3). Section in the mass reveals an inflammatory aspect surrounding an abscess with a wooden toothpick. The postoperative progression was simple. The pathology confirms the diagnosis of actinomycosis by

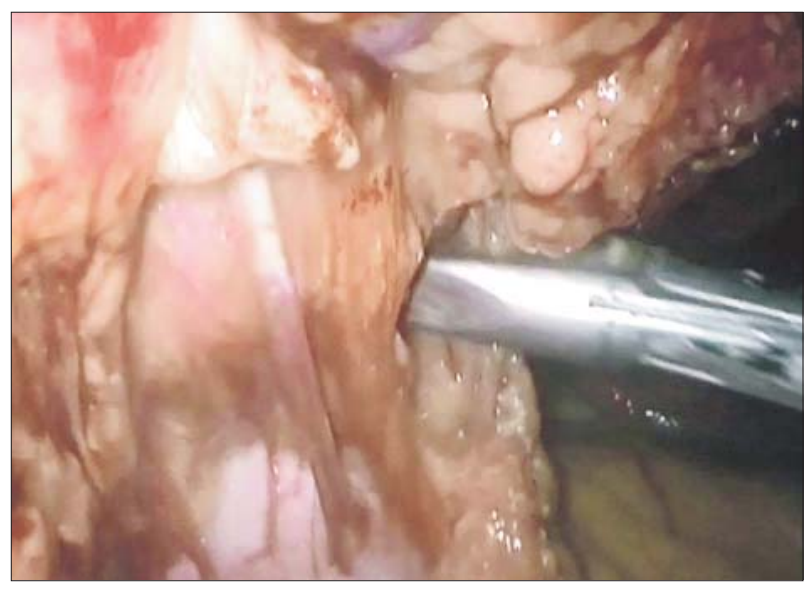

Figure 3. Laparoscopic resection of a large omentum mass, adjacent to the right colic angle, adherent to the anterior abdominal wall

the presence of PAS positive colonies of Actinomyces in a macrophage-rich granulation tissue. Penicillin treatment is done for one month.

The patient returns after 8 years with a trocar incisional hernia at the extraction site of the operative specimen. Mesh treatment of hernia allowed for abdominal wall biopsy and hernia sac resection; no actinomycosis lesions have been found.

Case 5. A 60-years-old female patient with many comorbidities (diabetes mellitus, ischemic cardiopathy) had been admitted for abdominal epigastric pain, episodes of constipation that led to suspicion of transverse colon cancer. Laboratory examinations show leukocytosis (WBC 15000/mmc) with neutrophilia (80\%), anemia (HGB $10 \mathrm{~g} / \mathrm{dl}, \mathrm{HCT} 30 \%$ ), high RPC. Abdominal ultrasound suspects a transverse colon tumor. Colonoscopy identifies a tight tumor stenosis on the transverse colon.

At intraoperative exploration there is a transverse colon tumor with invasion of the abdominal wall (Fig. 4). Intraoperative histopathological examination excludes malignancy. Segmental colectomy is performed with ablation of the abdominal wall invaded, ablation of the large omentum and colo-colic anastomosis.

On the section we observed an inflammatory tumor encompassing the transverse colon, the large omentum, the mesocolon and the abdominal wall with whitish areas, granules, 


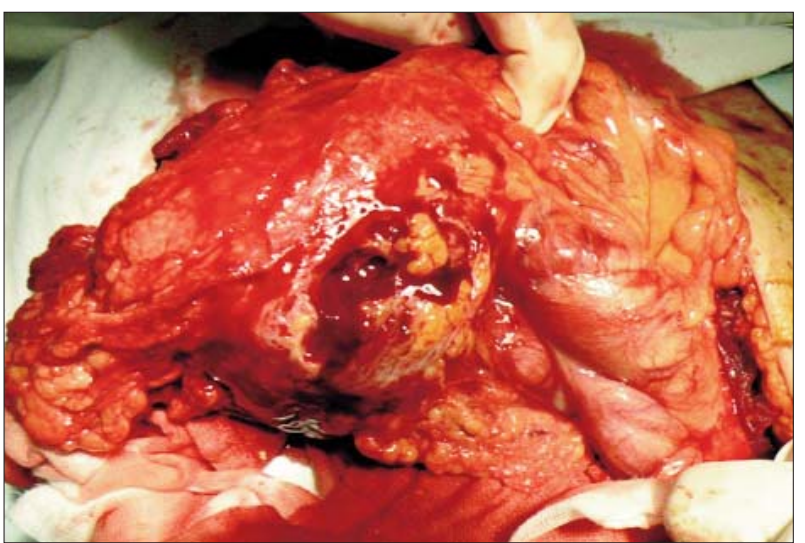

Figure 4. Transverse colon actinomycosis, intraoperative view

necrosis, abscesses (Fig. 5). The pathology revealed an inflammatory process that infiltrated the colon, pericolic fat with abscesses, in which colonies of Actinomyces israelii are found (Fig. 6). Penicillin treatment is performed for one month. The patient returns after 4 months with a parietal abscess, which is surgically drained. After treatment with penicillin and doxycycline for another month he is declared cured.

\section{Discussion}

Actinomycosis occurs worldwide, with higher prevalence rates in areas with low socioeconomic status and poor dental hygiene. In western nations, actinomycosis is very rare (USA - 1 case per 300.000 persons, Germany 1 case per 100.000 persons) (3). For unknown reasons, men are affected more commonly than women, except for pelvic actinomycosis. Most cases are reported in middle-aged adults. Actinomycosis of the abdomen and pelvis accounts for $10-20 \%$ of reported cases.

In Romania, T. Ionescu reported in 1901 the first case of abdominal actinomycosis requiring surgery, followed by other reports on actinomycosis: Bordescu (1914) - 4 cases; Câmpeanu (2004) - 1 case (hepatic); Palade (2009) - 1 case (abdominal and retroperitoneal), Andronic (2009) - 5 cases (pelvic) $(3,4)$.

In the large bowel, the most common of actinomycosis is the right colon and especially the cecum. In this location it can mimic a colon

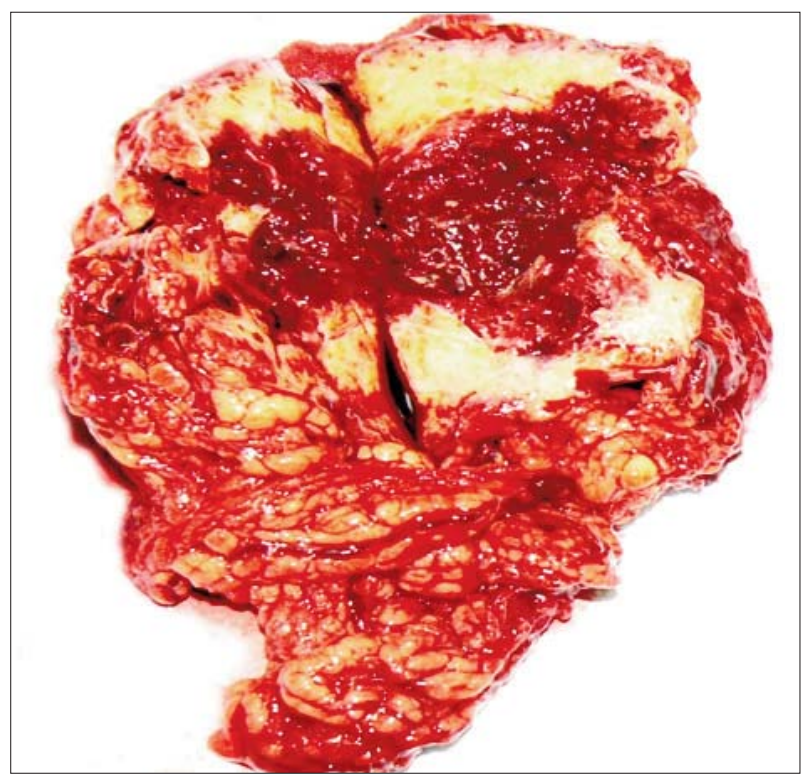

Figure 5. Actinomycosis - operative specimen on the section

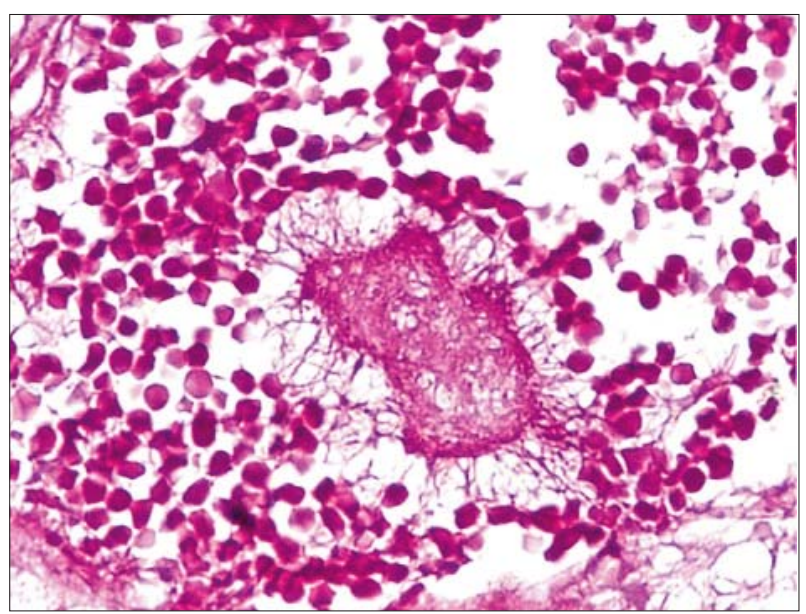

Figure 6. Abdominal actinomycosis. PAS Positive Actinomyces israelii Colony, $\mathrm{X} 20$

cancer $(5,6)$, as it was also in our cases. The transverse colon is less affected, and it can also mimic colon cancer (7). Actinomycosis of the sigmoid colon can present as diverticulitis or cancer (8).

Risk factors that favor the disease are: recent surgery or abdominal trauma, endoscopic procedures, visceral perforations (intestinal, appendicular, sigmoid diverticula) (9), foreign bodies (fish perforations, toothpicks) (10), biliary calculi lost in the peritoneum (11), one of the cases presented may be caused by a toothpick; 
genital actinomycosis was described only in association with IUD, and the colonization rate (1.6-44\%) increases with IUD maintenance duration (mean 8 years) (12); immunosuppressed patients: radio - chemotherapy, diabetes mellitus.

Abdominal actinomycosis has nonspecific symptoms. The most common symptoms are low-grade fever, weight loss, fatigue, changes in bowel habits, abdominal discomfort, nausea, vomiting, and palpable mass, as in our cases. Clinical presentation may mimic other chronic diseases such as granulomatous diseases (Crohn's disease) (13) or malignant lesions (14). Preoperative diagnosis is rare and is established only in less than $10 \%$ of cases; all our cases have been postoperative diagnosed by pathology.

Imaging studies are nonspecific as well. CT scan findings of an infiltrative, abdominal mass with unusual aggressiveness and heterogeneous contrast enhancement may suggests actinomycosis, especially in patients with fever, leukocytosis or long-term use of intrauterine contraceptive devices. In case of an abdominal abscess, the preoperative diagnosis of actinomycosis can be confirmed by percutaneous ultrasound-guided fine-needle aspiration (15). Frequently, final diagnosis is only made post operatively and is based on culture of the organisms, or the presence of "sulfur granules" in the specimen.

Medical treatment with a high dose penicillin should be tried first in uncomplicated cases (16) and surgery limited to complications or persistent disease. Surgery is often performed because of a difficulty in diagnosis. Surgery and antibiotics are required in the case of complicated disease. Combined medical and surgical treatment achieves a cure in about $90 \%$ of cases (8); we had an initial cure rate of 3 out of 5 patients, the other 2 had recurrences that had been finally cured by antibiotics.

Surgical removal of the tumoral lesion with resection or drainage, supplemented with longterm antibiotic therapy is recommended, such as with parenteral penicillin $\mathrm{G}$ followed by oral penicillin or amoxicillin for up to 12 months (17). Tetracycline, erythromycin, clindamycin can be given in those with penicillin allergy (18).

\section{Conclusions}

Abdominal actinomycosis should always be included in the differential diagnosis of abdominal tumors. Preoperative diagnosis, difficult but possible, can avoid surgery. Treatment with antibiotic (penicillin) iv 2-6 weeks, followed by oral therapy for 6 months is necessary for the healing of the disease. Postoperative control is mandatory, with relapses possible.

\section{Conflict of Interest}

The authors declare no conflicts of interests.

\section{References}

1. Caplan E, Deputy M, Arul D, Wilson J. Actinomycosis of the omentum with invasion of the abdominal wall, small bowel and transverse colon mimicking malignancy. BMJ Case Rep. 2019; 12(1). pii: bcr-2018-227728.

2. Yang SS, Im YC. Severe abdominopelvic actinomycosis with colon perforation and hepatic involvement mimicking advanced sigmoid colon cancer with hepatic metastasis: a case study. BMC Surg. 2018; 18(1):51.

3. Andronic D, Lupascu C, Târcoveanu E, Georgescu S, Neacsu C, Ferariu D, Crumpei F. Present trends in abdominal actinomycosis. Chirurgia (Bucur). 2009;104(4):439-46.

4. Palade R, Nastasescu T, Suliman E, Simion G. Tumoral form of abdominal and retroperitoneal actinomycosis.Chirurgia (Bucur). 2009;104(4):477-81.

5. Näf F, Enzler-Tschudy A, Kuster SP, Uhlig I, Steffen T. Abdominal actinomycosis mimicking a malignant neoplasm Surg Infect (Larchmt). 2014;15(4):462-3.

6. Filippou D, Psimitis I, Zizi D, Rizos S. A rare case of ascending colon actinomycosis mimicking cancer. BMC Gastroenterol. 2005;5:1.

7. Ergül Z, Hoca O, Karahan MA, Seker D, Hücümenoglu S, Ozakkoyunlu S. A transverse colonic mass secondary to Actinomyces infection mimicking cancer. Turk J Gastroenterol. 2008;19(3):200-1.

8. Privitera A, Milkhu CS, Datta V, Rodriguez-Justo M, Windsor A, Cohen CR. Actinomycosis of the sigmoid colon: A case report World J Gastrointest Surg. 2009;1(1):62-4.

9. Petrie BA, Schwartz SI, Saltmarsh GF. Intra-abdominal actinomycosis in association with sigmoid diverticulitis. Am Surg. 2014; 80(6):E157-9.

10. Hsieh YC, Chang YY, Lee KC. Colonic actinomycosis mimicking a fish bone-related granuloma. Clin Gastroenterol Hepatol. 2012; 10(10):e81-2

11. Vanoeteren X, Devreese K, De Munter P. Abdominal actinomycosis: a rare complication after cholecystectomy. Acta Clin Belg. 2014;69(2):152-6.

12. Valbø A, Rønning EJ, Aaberg M. Actinomycosis as a complication of intrauterine device use. Tidsskr Nor Laegeforen. 2010;130(8): 830-2.

13. Willms A, Schaaf S, Güsgen C, Waldeck S, Schwab R. Abdominal 
actinomycosis: a rare differential diagnosis to colon carcinoma and Morbus Crohn. Z Gastroenterol. 2014;52(6):569-72.

14. Acquaro P, Tagliabue F, Confalonieri G, Faccioli P, Costa M. Abdominal wall actinomycosis simulating a malignant neoplasm: Case report and review of the literature. World J Gastrointest Surg. 2010;2:247-50.

15. Goldwag S, Abbit PL, Watts B. Case reports: percutaneous drainage of periappendiceal actinomycosis. Clin Radiol. 1991; 44:422-424.

16. Zamani F, Sohrabi M. Clinical, Endoscopic, and Histopathological
Aspects of Sigmoid Actinomycosis; A Case Report and Literature Review. Middle East J Dig Dis. 2015;7(1):41-4.

17. Akbulut S, Yagmur Y, Gumus S, Sogutcu N, Demircan F. Actinomyces-induced inflammatory myofibroblastic tumor of the colon: A rare cause of an abdominal mass Int J Surg Case Rep. 2015:9:15-18.

18. Valdés-Peregrina EN, Bonifaz A, Arteaga-Sarmiento JF, HernándezGonzález M. Primary intestinal actinomycosis in ilium and colon. A case report and review of the literature. Rev Esp Patol. 2018;51(4):253-6. 